\title{
Thermal Decomposition Kinetics and Compatibility of 3,5-difluoro-2,4,6-trinitroanisole (DFTNAN)
}

\author{
Fei Hu ${ }^{1}$, Lin-Jian Wang ${ }^{1}$, Wei Zhao ${ }^{1}$, Yu-Cun Liu ${ }^{1, *}$, Su-Ming Jing ${ }^{1, *}$, Ping Liu ${ }^{2}$ and Jin-Xuan He ${ }^{3, *}$ \\ 1 School of Environment and Safety Engineering, North University of China, Taiyuan 030051, China; \\ B1914079@st.nuc.edu.cn (F.H.); S1914007@st.nuc.edu.cn (L.-J.W.); S1814082@st.nuc.edu.cn (W.Z.) \\ 2 Chongqing Hongyu Precision Industry Group Co., Ltd., Chongqing 402760, China; 18234138606@sohu.com \\ 3 Science and Technology on Aerospace Chemical Power Laboratory, Hubei Institute of Aerospace \\ Chemotechnology, Xiangyang 441003, China \\ * Correspondence: lyc2ct@vip.sina.com (Y.-C.L.); 20160075@nuc.edu.cn (S.-M.J.); \\ hejinxuan42@sina.com (J.-X.H.)
}

Citation: Hu, F.; Wang, L.J.; Zhao, W.; Liu, Y.-C.; Jing, S.-M.; Liu, P.; He, J.-X. Thermal Decomposition Kinetics and Compatibility of 3,5-difluoro2,4,6-trinitroanisole (DFTNAN). Materials 2021, 14, 4186. https:// doi.org/10.3390/ma14154186

Academic Editors: Daniela Kovacheva and Nicolas Sbirrazzuoli

Received: 18 June 2021

Accepted: 22 July 2021

Published: 27 July 2021

Publisher's Note: MDPI stays neutral with regard to jurisdictional claims in published maps and institutional affiliations.

Copyright: (c) 2021 by the authors. Licensee MDPI, Basel, Switzerland. This article is an open access article distributed under the terms and conditions of the Creative Commons Attribution (CC BY) license (https:/ / creativecommons.org/licenses/by/ $4.0 /)$.

\begin{abstract}
In this paper, the thermal decomposition behavior of 3,5-difluoro-2,4,6-trinitroanisole (DFTNAN) was studied by differential scanning calorimetry (DSC) and thermogravimetry (TG) by using different heating rates $\left(2,5,10,15^{\circ} \mathrm{C} \cdot \mathrm{min}^{-1}\right)$. Subsequently, the kinetic and thermodynamic parameters of non-isothermal thermal decomposition of DFTNAN were calculated. The critical temperature of thermal explosion $\left(T_{\mathrm{b}}\right)$ and self-accelerating decomposition temperature $\left(T_{\mathrm{ASDT}}\right)$ were determined to be $249.03{ }^{\circ} \mathrm{C}$ and $226.33^{\circ} \mathrm{C}$, respectively. The compatibility of DFTNAN with a number of high explosives (cyclo-1,3,5-trimethylene-2,4,6-trinitramine (RDX), 1,3,5,7-tetranitro1,3,5,7-tetrazocine (HMX), 2,4,6,8,10,12-hexanitro-2,4,6,8,10,12-hexaaza-tetracyclo-[5.5.0.05,9.03,11]dodecane (CL-20) and dihydroxylammonium 5,5'-bistetrazole-1,1'-diolate (TKX-50)) was studied at different mass ratios using DSC. The criteria to judge the compatibility between the materials were based on a standardization agreement (STANAG 4147). The thermodynamic study results revealed that DFTNAN possessed superior thermal safety and stability. The experimental of compatibility results indicated that the mass ratios of the high explosives in the DFTNAN/RDX, DFTNAN/HMX and DFTNAN/CL-20 compositions more than 40\%, 60\% and 70\% exhibited good compatibility, whereas DFTNAN/TKX-50 demonstrated poor compatibility.
\end{abstract}

Keywords: DFTNAN; cast explosives; thermal behavior; compatibility

\section{Introduction}

The melt-cast explosive is a mixed explosive material that can be cast in the molten state [1]. As the melt-cast explosive can adapt to various shapes and has a comprehensive performance, it represents a military grade mixed explosive. It is widely used in the loading of grenades, armor piercing bombs, aerial bombs, mine and missile warheads [2,3], etc. The liquid phase carrier of the melt-cast explosive is a key component. As a special energetic binder [4], the melt-casting carrier can not only improve the safety of highenergy explosives alone [5], but also enhance the structural integrity and mechanical properties of propellant and ammunition charges [6-8]. Compared with ordinary polymer binder, it has environmental friendliness and higher economic benefits $[9,10]$. For long, 2,4,6-trinitrotoluene (TNT) has been widely used as a carrier of the melt-cast explosive. With the requirement of low vulnerability of the military explosives put forward in the 1970s, TNT no longer meets the requirements for developing the modern weapons and ammunition [11]. In addition, TNT as the liquid carrier of the explosives has been improved by adding other high-energy materials to form a low eutectic material. Overall, an effective synthesis and design of the liquid phase carrier is needed to replace TNT [12].

Currently, a number of melt-cast explosive carriers which are expected to replace TNT have been synthesized, such as 2,4-dinitrobenzene (DNAN), 3,4-dinitropyrazole 
(DNP) [13], 1-methyl-3,4,5-trinitropyrazole (MTNP) [14], 1-methyl-2,4,5-trinitroimidazole (MTNI) [15,16], 3,4-dinitrofurazanfuroxan (DNTF) [17], 1-methyl-3,5-dinitropyrazole (DNMT) [18], 1-nitroamino-2,3-dinitrate propane (NG-N1) [19], etc. However, these suffer from different shortcomings and do not meet the requirements of widespread application.

2,4,6-trinitro-3,5-difluorophenyl methyl ether (DFTNAN) is a new class of fusion casting carrier [20]. Its structure is shown in Figure 1. DFTNAN possesses high density $\left(1.81 \mathrm{~g} \cdot \mathrm{cm}^{-3}\right)$, low melting point $\left(82^{\circ} \mathrm{C}\right)$, high decomposition temperature $\left(285^{\circ} \mathrm{C}\right)$ and low sensitivity to external stimuli [20]. In addition, it demonstrates a superior detonation velocity and detonation pressure. Its thermal behavior and compatibility have not been reported in the literature so far, thus, requiring in-depth analysis.

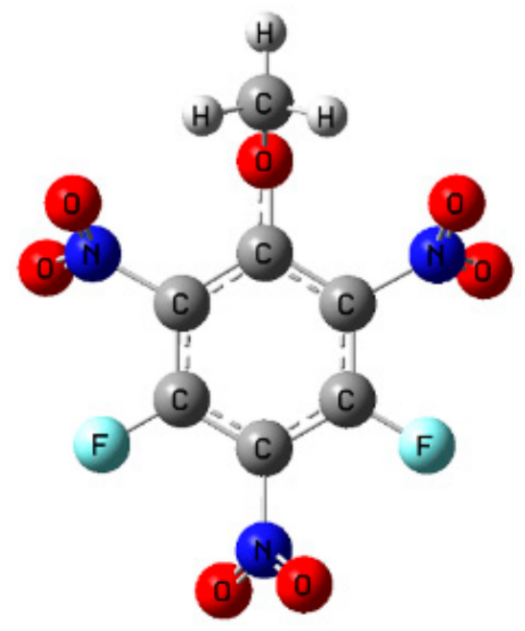

Figure 1. Chemical structure of DFTNAN.

Therefore, in this study, the thermal decomposition behavior of DFTNAN was studied by differential scanning calorimetry (DSC) and thermogravimetry (TG). The non-isothermal thermal decomposition kinetics of DFTNAN was explored by using the Kissinger and Ozawa methods. The apparent activation energy and pre-exponential factor were obtained subsequently. At the same time, the thermodynamic parameters, including the peak decomposition temperature, self-accelerating decomposition temperature and thermal explosion critical temperature were determined, along with evaluating the thermal safety of DFTNAN. Based on the STANAG 4147 standard, the compatibility of DFTNAN with cyclo1,3,5-trimethylene-2,4,6-trinitramine (RDX), 1,3,5,7-tetranitro-1,3,5,7-tetrazocine (HMX), 2,4,6,8,10,12-hexanitro-2,4,6,8,10,12-hexaaza-tetracyclo-[5.5.0.05,9.03,11]-dodecane (CL-20) and dihydroxylammonium 5,5'-bistetrazole-1,1'-diolate (TKX-50) composite explosives were evaluated at different mass ratios by DSC. The findings obtained in this study are expected to act as a benchmark for the application of DFTNAN in melt-casting explosives.

\section{Experimental}

\subsection{Materials}

DFTNAN was prepared in the lab with a purity of $98 \%$.

The solid high energy explosives, technical grade RDX, HMX, CL-20 and TKX-50 with a purity of more than $97 \%$ were supplied by Qingyang Chemical Industry Corporation (Liaoning, China), Gansu Yinguang Chemical Industry Group (Gansu China, North Industries Group (Beijing, China) and Liming Research Institute of Chemical Industry (Henan, China), respectively.

\subsection{Preparation of Samples}

Preparation of the test sample for the thermal decomposition analysis: DFTNAN was dried in an explosion-proof oven at $60{ }^{\circ} \mathrm{C}$ for $4 \mathrm{~h}$, followed by grinding with an agate mortar and passing through 120 mesh screen. 
Preparation of the sample for the compatibility test: The binary mixtures of DFTNAN with RDX, HMX, CL-20 and TKX-50 were prepared at different mass ratios, as shown in Table 1.

Table 1. Test samples information.

\begin{tabular}{|c|c|c|c|c|c|c|c|c|c|c|c|}
\hline Test Sample & \multirow{3}{*}{ Number } & Test Sample & \multicolumn{9}{|c|}{ Number } \\
\hline \multirow{2}{*}{ Single System } & & \multirow{2}{*}{ Mixture System } & \multicolumn{9}{|c|}{ Mass Ratio (\%) } \\
\hline & & & $9: 1$ & $8: 2$ & $7: 3$ & $6: 4$ & $5: 5$ & $4: 6$ & $3: 7$ & $2: 8$ & 1:9 \\
\hline DFTNAN & A1 & DFTNAN/RDX & B1 & B2 & B3 & B4 & B5 & B6 & B7 & B8 & B9 \\
\hline RDX & $\mathrm{A} 2$ & DFTNAN/HMX & $\mathrm{C} 1$ & $\mathrm{C} 2$ & C3 & $\mathrm{C} 4$ & $\mathrm{C} 5$ & C6 & C7 & $\mathrm{C} 8$ & C9 \\
\hline HMX & $\mathrm{A} 3$ & DFTNAN/CL-20 & D1 & D2 & D3 & D4 & D5 & D6 & D7 & D8 & D9 \\
\hline CL-20 & A4 & DFTNAN/TKX-50 & E1 & E2 & E3 & $\mathrm{E} 4$ & E5 & E6 & E7 & E8 & E9 \\
\hline TKX-50 & A5 & \multicolumn{10}{|l|}{ 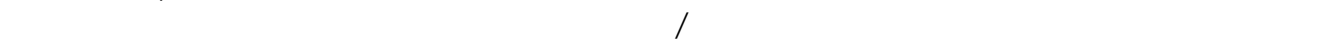 } \\
\hline
\end{tabular}

The components were dried in an explosion-proof oven at $60{ }^{\circ} \mathrm{C}$ for $4 \mathrm{~h}$. Afterwards, DFTNAN was completely melted, and the solid high explosive (RDX/HMX/CL-20/TKX-50) was added in batches as per the relation shown in Table 1 . The capillary stirring was employed during the process. After the addition of the explosive, the mixture was stirred for $5 \mathrm{~min}$, followed by cooling to room temperature. The solidified casting explosives with different compositions were ground into powder form with an agate mortar.

\subsection{Characterization}

Thermal stability: The thermal decomposition behavior the samples were determined in the temperature range $50-350{ }^{\circ} \mathrm{C}$ using the heating rates of $2,5,10$ and $15{ }^{\circ} \mathrm{C} \cdot \mathrm{min}^{-1}$ by, respectively, employing HCT-1 (HENVEN Instruments, Beijing, China) and TAG 5500 (TA Instruments, New Castle, DE, USA) under $\mathrm{N}_{2}$ atmosphere. For DSC, about 1.0 1.5 mg sample mass was taken in the aluminum pans with cover. On the other hand, the TG sample weighing about $5.0 \mathrm{mg}$ was taken in a ceramic crucible.

Compatibility: The samples $(1.0 \mathrm{mg})$ taken in the aluminum pans with cover were characterized by using HCT-1 in the temperature range $50{ }^{\circ} \mathrm{C}$ to $350{ }^{\circ} \mathrm{C}$ at a heating rate of $5{ }^{\circ} \mathrm{C} \cdot \mathrm{min}^{-1}$ from under $\mathrm{N}_{2}$ atmosphere. For assessing the compatibility, the peak decomposition of DFTNAN was compared with the peak decomposition of the mixtures (DNTNAN and RDX/HMX/CL-20/TKX-50).

\section{Results and Discussion}

\subsection{Thermal Decomposition Behavior of DFTNAN}

\subsubsection{DSC Analysis}

The DSC curves of DFTNAN under different conditions acquired using a heating rate of $5{ }^{\circ} \mathrm{C} \cdot \mathrm{min}^{-1}$ are presented in Figure 2. In the open condition, the DSC curve of DFTNAN demonstrated two endothermic peaks at $82^{\circ} \mathrm{C}$ and $211^{\circ} \mathrm{C}$, which indicated the melting and evaporation processes, respectively. However in the closed condition, an endothermic peak and an exothermic peak were observed, which corresponded to the melting at $82{ }^{\circ} \mathrm{C}$ and decomposition at $273{ }^{\circ} \mathrm{C}$. In the open condition, no decomposition was detected up to $273{ }^{\circ} \mathrm{C}$, as DFTNAN reached the boiling point before reaching the decomposition temperature.

The DSC curves of DFTNAN acquired using the heating rates of $2,5,10$ and $15^{\circ} \mathrm{C} \cdot \mathrm{min}^{-1}$ are shown in Figure 3. As shown, the temperature of the decomposition peak $\left(T_{\mathrm{p}}\right)$ increased on enhancing the heating rate, with the peak becoming wider. However, the temperature of the melting peak exhibited only a slight change. The observed shifting of the exothermic peak to the high temperature might be attributed to an increment in the thermal effect per unit time and temperature difference. Further, the reduction in the reaction time and incomplete decomposition reaction on enhancing the heating rate also contributed to this effect [21]. Thus, the synthesis leads to a lag in the heat release. The epitaxial starting 
temperature $\left(T_{\mathrm{eo}}\right)$, peak temperature $\left(T_{\mathrm{p}}\right)$ and end decomposition temperature $\left(T_{\mathrm{f}}\right)$ of DFTNAN at different heating rates are listed in Table 2.

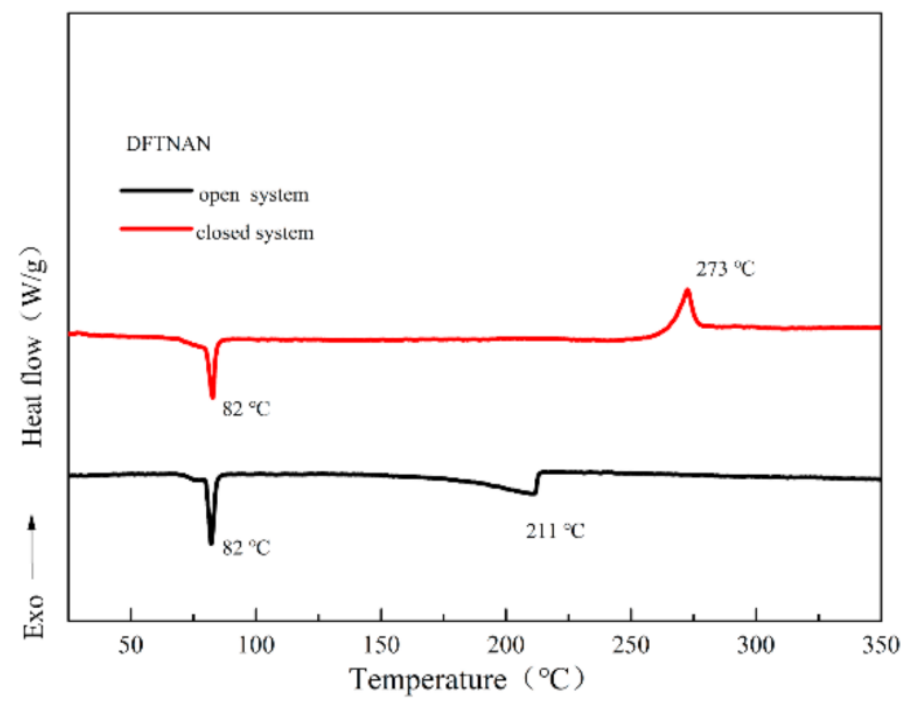

Figure 2. DSC curves for DFTNAN at heating rate $5{ }^{\circ} \mathrm{C} \mathrm{min}^{-1}$ (under different conditions).

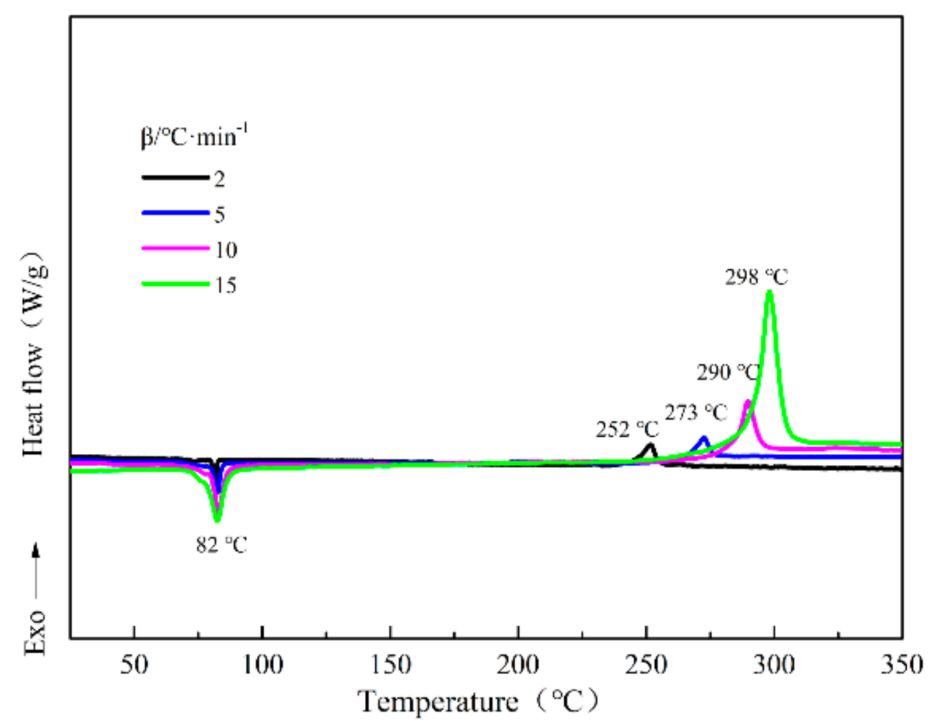

Figure 3. DSC curves for DFTANA at different heating rates of 2, 5, 10 and $15{ }^{\circ} \mathrm{C} \mathrm{min}-1$.

Table 2. DSC data of DFTNAN at different heating rates.

\begin{tabular}{cccc}
\hline $\boldsymbol{\beta} /{ }^{\circ} \mathbf{C} \cdot \mathbf{m i n}^{-\mathbf{1}}$ & $\boldsymbol{T}^{\prime}{ }_{\text {eo }} /{ }^{\circ} \mathbf{C}$ & $\boldsymbol{T}_{\mathbf{p}} /{ }^{\circ} \mathbf{C}$ & $\boldsymbol{T}_{\mathbf{f}} /{ }^{\circ} \mathbf{C}$ \\
\hline 2 & 246.20 & 251.64 & 255.41 \\
5 & 266.63 & 272.59 & 275.76 \\
10 & 285.45 & 289.72 & 295.12 \\
15 & 291.17 & 297.99 & 304.02 \\
\hline
\end{tabular}

\subsubsection{TG Analysis}

The TG-DTG curves of DFTNAN at various heating rates are shown in Figure 4. Only one step decomposition was observed in the TG curves, and the mass loss rate was close to $100 \%$. It indicated that the decomposition of DFTNAN was a complete and continuous process. On increasing the heating rate, the temperature $\mathrm{T}_{\mathrm{V}}$ at the maximum mass loss rate increased, as expected. The observed behavior was consistent with the trend observed 
in the DSC curves: on increasing the heating rate, $T_{\mathrm{p}}$ and $T_{\mathrm{V}}$ at the maximum mass loss rate exhibit an increase. A significant difference was observed between the $T_{\mathrm{V}}$ (DTG) and $T_{\mathrm{p}}$ (DSC) values at different heating rates, which was due to the fact that the DSC analysis was performed in the closed conditions, and the TG analysis was carried out in the open condition.

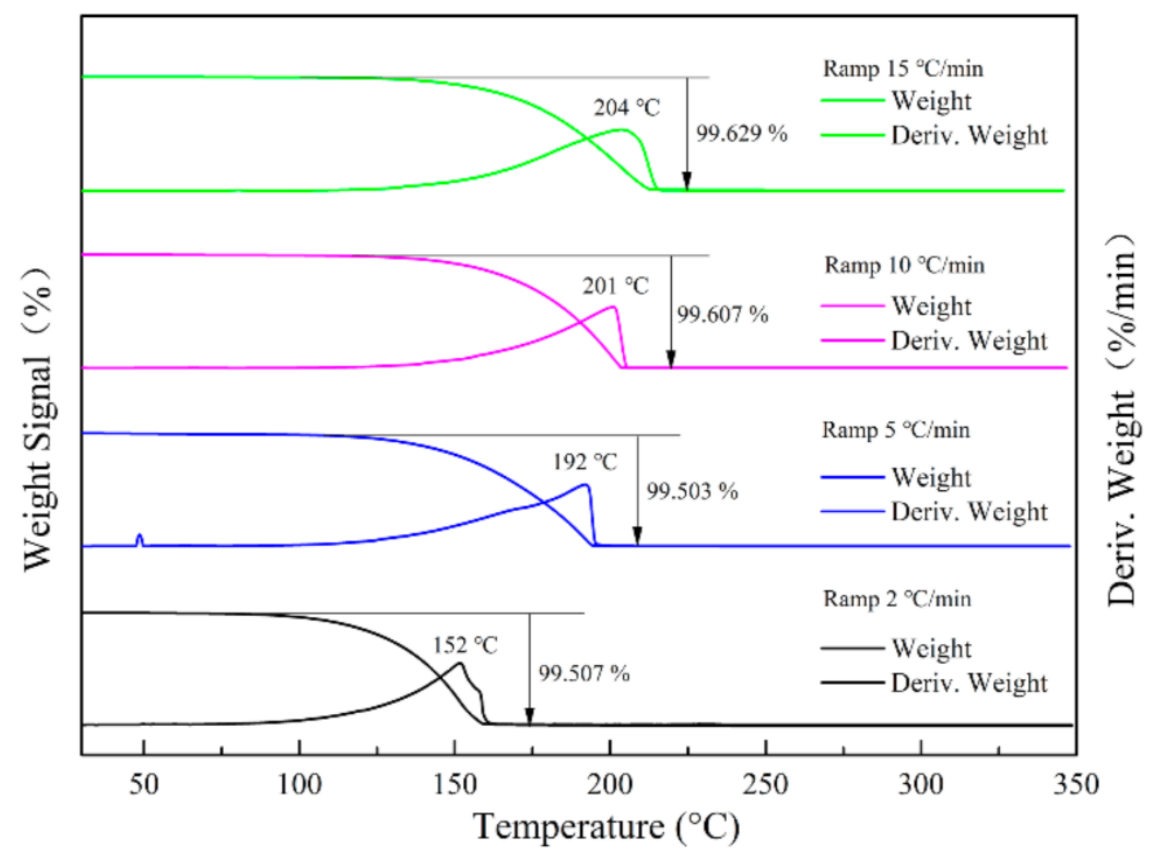

Figure 4. TG curves for DFTANA at different heating rates of 2, 5, 10 and $15{ }^{\circ} \mathrm{C} \mathrm{min}^{-1}$.

\subsubsection{Non-Isothermal Decomposition Kinetics}

In order to obtain the apparent activation energy $\left(E_{\mathrm{k}}\right)$ and pre-exponential factor $\left(A_{\mathrm{k}}\right)$ for the thermal decomposition of DFTNAN, the Ozawa and Kissinger methods were applied. The equations for the Kissinger (1) and Ozawa (2) methods can be written as follows [22,23]:

$$
\begin{gathered}
\ln \frac{\beta_{\mathrm{i}}}{T_{\mathrm{pi}}^{2}}=\ln \frac{A_{\mathrm{k}} R}{E_{\mathrm{k}}}-\frac{E_{\mathrm{k}}}{R T_{\mathrm{pi}}}, i=1,2, \ldots, 4 \\
\log \beta_{\mathrm{i}}=\log \left(\frac{A_{\mathrm{k}} E_{\mathrm{o}}}{R \mathrm{~g} \alpha}\right)-2.315-\frac{0.4567 E_{\mathrm{o}}}{R T_{\mathrm{pi}}}, \mathrm{i}=1,2,3, \ldots
\end{gathered}
$$

where, $R$ is the gas constant $\left(8.314 \mathrm{~J} \cdot \mathrm{mol}^{-1} \cdot \mathrm{K}^{-1}\right), \beta_{i}$ is the linear heating rate $\left(\mathrm{K} \cdot \mathrm{min}^{-1}\right)$ and $T_{\mathrm{pi}}$ corresponds to the peak decomposition temperature in case the heating rate is $\beta_{i}(\mathrm{~K})$.

As per the Kissinger and Ozawa equations, the values of $\ln \frac{\beta_{i}}{T_{\mathrm{pi}}^{2}}$ and $\log \beta_{i}$ were plotted against $\frac{1}{T_{\mathrm{pi}}}$, respectively. The regression equation and correlation coefficient were subsequently obtained, where the $E_{\mathrm{k}}$ and $E_{\mathrm{o}}$ values were determined from the slope, and the values of $A_{\mathrm{k}}$ were obtained from the intercept, as shown in Table 3. As observed, the apparent activation energy of DFTNAN obtained by the Kissinger method was in good agreement with the energy obtained by the Ozawa method. Further, the linear correlation coefficients were noted to be close to 1 , indicating that the calculation results were reliable.

\begin{tabular}{|c|c|c|c|c|c|c|c|c|c|}
\hline \multicolumn{3}{|c|}{ Kissinger's Method } & \multicolumn{2}{|c|}{ Ozawa's Method } & \multirow{2}{*}{$T_{\mathrm{ASDT}} /{ }^{\circ} \mathrm{C}$} & \multirow{2}{*}{$T_{\mathrm{b}} /{ }^{\circ} \mathrm{C}$} & \multirow{2}{*}{$\begin{array}{c}\Delta H^{\neq} \\
\mathrm{kJ} \cdot \mathrm{mol}^{-1}\end{array}$} & \multirow{2}{*}{$\begin{array}{c}\Delta S^{\neq} \\
\mathrm{kJ} \cdot \mathrm{mol}^{-1} \cdot \mathrm{K}^{-1}\end{array}$} & \multirow{2}{*}{$\begin{array}{c}\Delta G^{\neq} \mathrm{I}^{\mathrm{kJ} \cdot \mathrm{mol}^{-1}}\end{array}$} \\
\hline$A_{\mathrm{k}} / \mathrm{min}^{-1}$ & $E_{\mathrm{k}} / \mathrm{kJ} \cdot \mathrm{mol}^{-1}$ & $R^{2}$ & $E_{\mathrm{o}} / \mathrm{kJ} \cdot \mathrm{mol}^{-1}$ & $R^{2}$ & & & & & \\
\hline $4.73 \times 10^{8}$ & 97.93 & 0.9977 & 101.78 & 0.9980 & 226.33 & 249.03 & 95.28 & -92.26 & 146.13 \\
\hline
\end{tabular}

Table 3. Thermal decomposition kinetic parameters, thermodynamic parameters and thermal safety parameters of DFTNAN. 


\subsubsection{Thermodynamic Parameters of Activation Reaction}

The entropy $\left(\Delta S^{\neq}\right)$, enthalpy $\left(\Delta H^{\neq}\right)$and Gibbs free energy $\left(\Delta G^{\neq}\right)$of activation of the exothermic decomposition of DFTNAN were calculated according to Equations (3)-(5) [24].

$$
\begin{gathered}
A=\frac{k T_{p}}{h} \exp \left(\frac{\Delta S^{\neq}}{R}\right) \\
\Delta H^{\neq}=E_{\mathrm{k}}-R T_{\mathrm{p}} \\
\Delta G^{\neq}=\Delta H^{\neq}-T_{\mathrm{p}} \Delta S^{\neq}
\end{gathered}
$$

where, $k$ is the Boltzmann's constant $\left(1.3807 \times 10^{-23} \mathrm{~J} \cdot \mathrm{K}^{-1}\right)$, and $h$ is the Planck's constant $\left(6.625 \times 10^{-34} \mathrm{~J} \cdot \mathrm{s}^{-1}\right)$.

By using the calculated data, $\Delta S^{\neq}, \Delta H^{\neq}$and $\Delta G^{\neq}$at $T_{\mathrm{p}}$ were calculated. The $\Delta S^{\neq}$ value was noted to be negative, as per the transition state theory, which indicated that the order of the transition state structure was increased. On the other hand, the $\Delta H^{\neq}$and $\Delta G^{\neq}$ values were observed to be positive, which indicated a non-spontaneous process related to the introduction of heat, thereby revealing the superior thermal stability of DFTNAN.

\subsubsection{Thermal Safety Parameters}

The critical temperature of thermal explosion $\left(T_{\mathrm{b}}\right)$ is a vital parameter to evaluate the safety of the materials and ascertain the transformation from thermal decomposition to thermal explosion [25]. On the other hand, the self-accelerating decomposition temperature $\left(T_{\mathrm{ASDT}}\right)$ represents the maximum allowable ambient temperature for practical application.

For DFTNAN, the polynomial regression method $\left(T_{\mathrm{ei}}=T_{\mathrm{eo}}+\alpha \beta_{i}+b \beta_{i}^{2}+c \beta_{i}^{3}\right)$ was used. For $\beta=0$, the epitaxial starting temperature $T_{\mathrm{eo}}$ was obtained more accurately and $T_{\mathrm{ASDT}}=T_{\mathrm{eo}}$ [26]. The $T_{\mathrm{b}}$ value was obtained by substituting $T_{\mathrm{eo}}$ in Equation (6) [27].

$$
T_{\mathrm{b}}=\left[E-\left(E^{2}-4 E R T_{\mathrm{eo}}\right)^{\frac{1}{2}}\right] / 2 R
$$

The values of $T_{\text {eo }}\left(T_{\mathrm{ASDT}}\right)$ and $\mathrm{T}_{\mathrm{b}}$ were determined to be $226.33{ }^{\circ} \mathrm{C}$ and $249.03{ }^{\circ} \mathrm{C}$, respectively. Therefore, the high epitaxial starting temperature and critical temperature of thermal explosion of DFTNAN revealed its superior thermal safety and stability at room temperature.

\subsection{Compatibility}

The compatibility is closely related to the safety and reliability of the explosives [28]. The compatibility of DFTNAN with the high energy solid explosives was evaluated by determining the maximum peak temperature difference $\Delta T_{\mathrm{p}}$ from DSC, according to the STANAG 4147 criterion [29] (Table 4).

The DSC curves of pure DFTNAN (A1), pure RDX (A2), pure HMX (A3), pure CL-20 (A4), pure TKX-50 (A5), DFTNAN/RDX (B1-B9), DFTNAN/HMX (C1 C9), DFTNAN/CL20 (D1 D9) and DFTNAN/TKX-50 (E1-E9) in the closed condition at a heating rate of $5{ }^{\circ} \mathrm{C} \cdot \mathrm{min}^{-1}$ are presented in Figures $5-8$. The corresponding evaluated compatibility values are summarized in Table 5.

As observed, the addition of the high explosives to DFTNAN significantly reduced the decomposition peak temperature of the mixed samples, especially on adding TKX-50. The reason for the observed behavior might be attributed to the partial solubility of the $\mathrm{N}$-nitramines explosives (RDX, HMX and CL-20) in DFTNAN. On increasing the temperature, a part of the N-nitramines explosive was dissolved in the melting DFTNAN. Due to the advanced decomposition of DFTNAN induced by the liquid N-nitramines explosive, the peak decomposition temperature of the DTNAN/N-nitramines explosive composition decreased correspondingly. However, TKX-50 is an energetic ionic salt, and the proton transfer may reduce the reaction barrier under thermal stimulation [30], leading 
to the formation of a molten mixture with melting DFTNAN. The led to the decomposition temperature of DFTNAN/TKX-50 decrease significantly.

Table 4. Evaluation standards of the compatibility for explosives.

\begin{tabular}{cl}
\hline Criteria $\triangle T_{\mathbf{p}}\left({ }^{\circ} \mathbf{C}\right)$ & \multicolumn{1}{c}{ Content } \\
\hline$<4$ & -the mixture is considered to be compatible \\
$4-20$ & $\begin{array}{l}\text {-the mixture is considered "moderately" incompatible (it is necessary } \\
\text { to apply other methods of determining the compatibility); } \\
>20\end{array}$ \\
-the mixture is considered to be incompatible
\end{tabular}

Table 5. Compatibility results of DFTNAN-based mixture explosives by DSC.

\begin{tabular}{|c|c|c|c|c|c|}
\hline System & Mass Ratios of Mixture & $\mathrm{OB} / \%$ & $T_{\mathrm{p}} /{ }^{\circ} \mathrm{C}$ & $\Delta T_{\mathrm{p}} /{ }^{\circ} \mathrm{C}$ & Compatibility Judgment \\
\hline DFTNAN & / & -43.01 & 273 & / & / \\
\hline \multirow[t]{5}{*}{ RDX } & / & -21.62 & 231 & / & / \\
\hline & $90: 10$ & -40.87 & 240 & 9 & "Moderately" incompatible \\
\hline & $80: 20$ & -38.73 & 224 & 7 & "Moderately" incompatible \\
\hline & $70: 30$ & -36.59 & 225 & 6 & "Moderately" incompatible \\
\hline & $60: 40$ & -34.46 & 227 & 4 & Compatible \\
\hline \multirow[t]{5}{*}{ DFTNAN/RDX } & $50: 50$ & -32.32 & 228 & 3 & Compatible \\
\hline & $40: 60$ & -30.18 & 228 & 3 & Compatible \\
\hline & $30: 70$ & -28.04 & 227 & 4 & Compatible \\
\hline & $20: 80$ & -25.90 & 229 & 2 & Compatible \\
\hline & $10: 90$ & -23.76 & 229 & 2 & Compatible \\
\hline \multirow[t]{5}{*}{ HMX } & / & -21.62 & 281 & / & / \\
\hline & $90: 10$ & -40.87 & 245 & 28 & Incompatible \\
\hline & $80: 20$ & -38.73 & 239 & 34 & Incompatible \\
\hline & $70: 30$ & -36.59 & 239 & 34 & Incompatible \\
\hline & $60: 40$ & -34.46 & 240,272 & 33,9 & Incompatible \\
\hline \multirow[t]{5}{*}{ DFTNAN/HMX } & $50: 50$ & -32.32 & 239,269 & 34,12 & Incompatible \\
\hline & $40: 60$ & -30.17 & 277 & 4 & Compatible \\
\hline & $30: 70$ & -28.04 & 277 & 3 & Compatible \\
\hline & $20: 80$ & -25.90 & 279 & 1 & Compatible \\
\hline & 10:90 & -23.76 & 279 & 2 & Compatible \\
\hline \multirow[t]{5}{*}{ CL-20 } & / & -10.96 & 237 & / & / \\
\hline & $90: 10$ & -39.81 & 210,231 & 24,42 & Incompatible \\
\hline & $80: 20$ & -36.60 & 207 & 66 & Incompatible \\
\hline & $70: 30$ & -33.40 & 207 & 66 & Incompatible \\
\hline & $60: 40$ & -30.19 & 209 & 63 & Incompatible \\
\hline \multirow[t]{5}{*}{ DFTNAN/CL-20 } & $50: 50$ & -26.98 & 209,244 & 64,7 & Incompatible \\
\hline & $40: 60$ & -23.78 & 208,243 & 65,6 & Incompatible \\
\hline & $30: 70$ & -20.57 & 239 & 2 & Compatible \\
\hline & $20: 80$ & -17.37 & 239 & 2 & Compatible \\
\hline & $10: 90$ & -14.16 & 240 & 3 & Compatible \\
\hline \multirow[t]{5}{*}{ TKX-50 } & / & -27.12 & 240,289 & / & / \\
\hline & $90: 10$ & -41.42 & 179 & 94 & Incompatible \\
\hline & $80: 20$ & -39.83 & 174 & 99 & Incompatible \\
\hline & $70: 30$ & -38.24 & 170 & 103 & Incompatible \\
\hline & $60: 40$ & -36.65 & 169 & 104 & Incompatible \\
\hline \multirow[t]{5}{*}{ DFTNAN/TKX-50 } & $50: 50$ & -35.06 & 160 & 113 & Incompatible \\
\hline & $40: 60$ & -33.48 & 161 & 112 & Incompatible \\
\hline & $30: 70$ & -31.89 & $160,214,294$ & 113,265 & Incompatible \\
\hline & $20: 80$ & -30.30 & $155,221,294$ & 118,195 & Incompatible \\
\hline & $10: 90$ & -28.71 & $154,225,301$ & $1,191,512$ & Incompatible \\
\hline
\end{tabular}




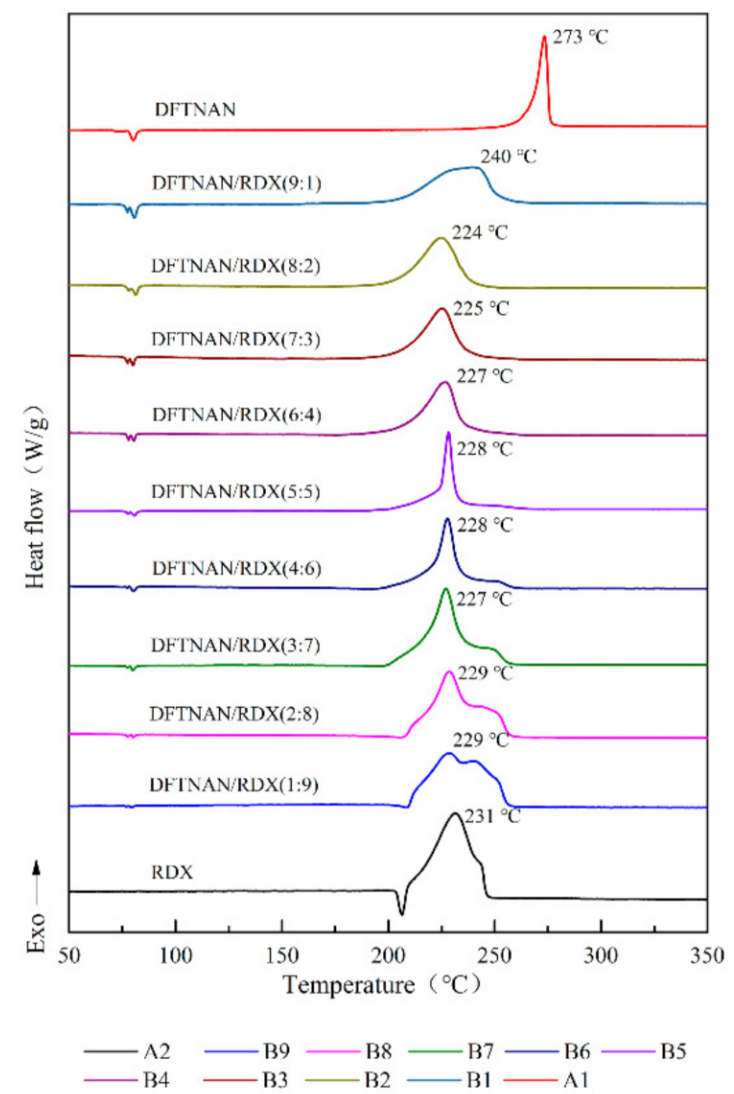

Figure 5. DSC curves of DFTNAN, RDX and mixtures with different ratios.

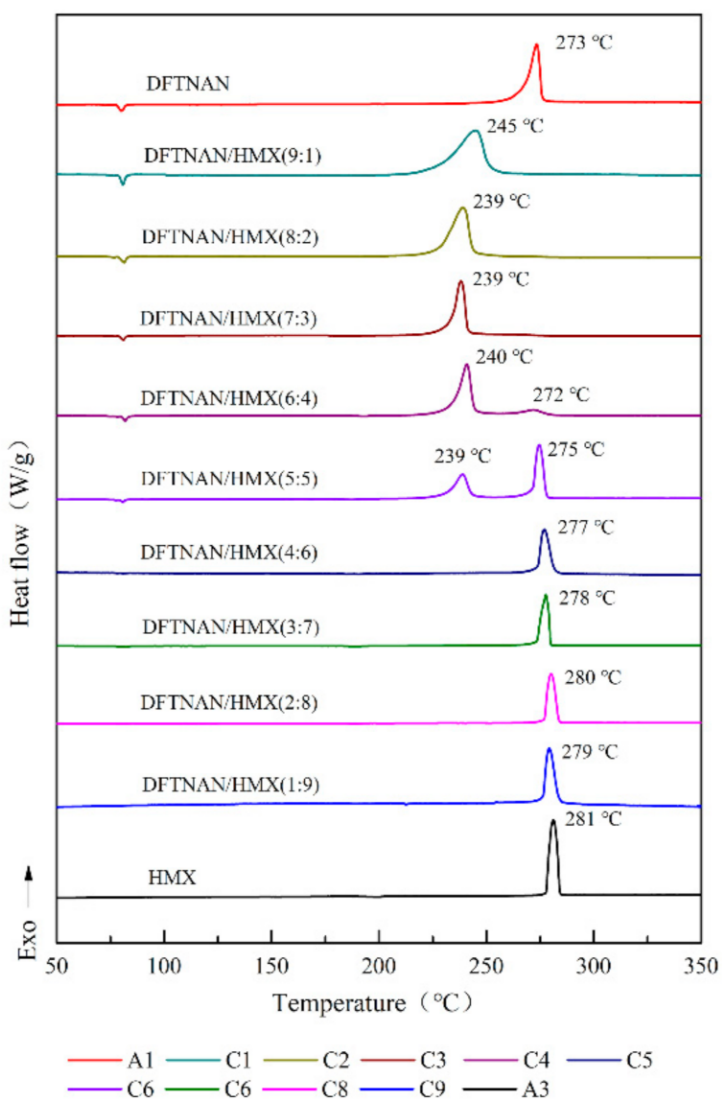

Figure 6. DSC curves of DFTNAN, HMX and mixtures with different ratios. 


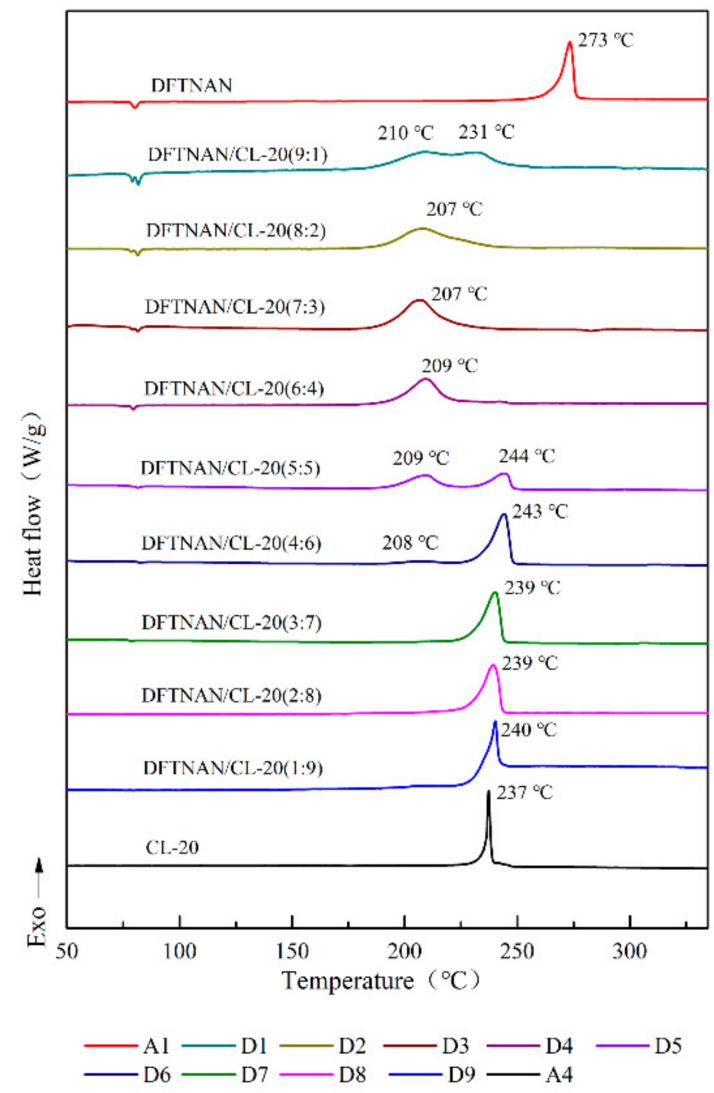

Figure 7. DSC curves of DFTNAN, CL-20 and mixtures with different ratios.

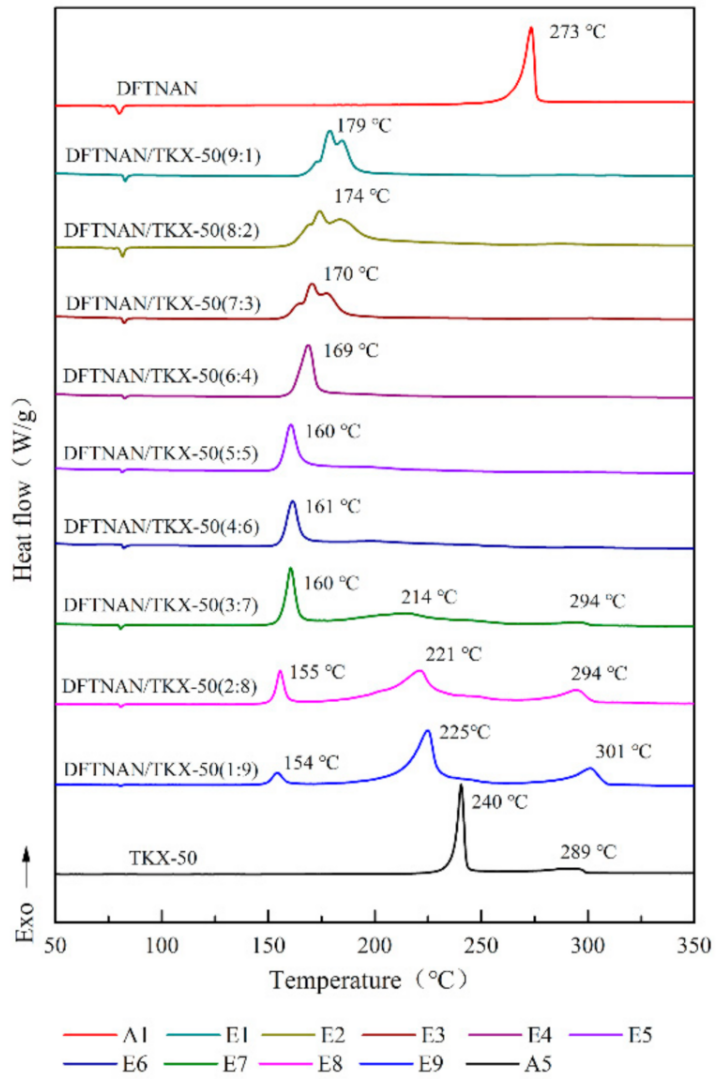

Figure 8. DSC curves of DFTNAN, TKX-50 and mixtures with different ratios. 
The solubility of the N-nitramines explosives in DFTNAN is limited. On enhancing the N-nitramines explosive content, the induction effect of the liquid N-nitramines explosive decreased. The peak decomposition temperature of the mixed samples was correspondingly affected. The DSC curves of the DFTNAN/N-nitramines composition are shown in Figures 5-7.

\subsubsection{DFTNAN/RDX}

As observed in Figure 5, there were an exothermic peak in DSC curves of samples B1-B9. The peak temperature observed in B1 sample was higher than $\mathrm{A} 2\left(237^{\circ} \mathrm{C}\right)$, which corresponded to the decomposition of DFTNAN. The $\Delta T_{\mathrm{p}}$ values for B1 sample was $9{ }^{\circ} \mathrm{C}$. The peak temperatures of the B2-B9 samples were lower than A2 $\left(237^{\circ} \mathrm{C}\right)$, which was ascribed to the decomposition of RDX. Apart from B2 and B3 samples which had the $\Delta T_{\mathrm{p}}$ values of 7 and $6{ }^{\circ} \mathrm{C}$, all other samples did not exceed $4{ }^{\circ} \mathrm{C}$. The $\Delta T_{\mathrm{p}}$ values of the samples indicated that RDX was compatible with DFTNAN, except for the mass ratio of 10:90, 20:80 and 30:70 exhibiting moderate incompatibility.

As reported in literature [31], the melting point of RDX is $207^{\circ} \mathrm{C}$. The DSC curve for the composition with a high content of DFTNAN exhibited no melting peak of RDX, whereas the melting peak appeared on increasing the RDX content. This was due to the reason that the low RDX content led to the partial dissolution of RDX through an autocatalytic reaction, thus, speeding up the decomposition rate of the whole system. The melting process was carried out together with the decomposition process, thus, that the melting peak of RDX did not appear in the DSC curve.

\subsubsection{DFTNAN/HMX}

There was a single exothermic peak in DSC curves of samples C1-C3, which was ascribed to the decomposition of DFTNAN. The peak temperatures of these samples were noted to be lower than A1. The $\Delta T_{\mathrm{p}}$ values for the C1-C3 samples were more than $20{ }^{\circ} \mathrm{C}$, while the result indicated these compositions to be incompatible. On further increasing the HMX content, the peak decomposition temperature of the mixed samples was correspondingly affected.

In Figure 6, the DSC curves for the samples C4 and C5 exhibited two exothermic peaks, which corresponded to the decomposition of DFTNAN and HMX. The first peak became weaker, whereas the second peak became stronger on increasing the HMX content. The $T_{\mathrm{p}}$ values for the first and second peaks for the samples were determined to be 33 and $34{ }^{\circ} \mathrm{C}$ or 9 and $12{ }^{\circ} \mathrm{C}$, respectively. As the HMX content was more than $60 \%$, the DSC curves for the C6-C9 samples displayed only a single exothermic peak, which was ascribed to the decomposition of HMX. The $\Delta T_{\mathrm{p}}$ values for the samples were noted to be $<4{ }^{\circ} \mathrm{C}$. This indicated that the DFTNAN/HMX composition with the mass ratios of 10:90, 20:80, 30:70 and 90:10 exhibited optimal compatibility. It should be noted that the melting endothermic peak of A3 was not observed due to the low heating rate [32].

\subsubsection{DFTNAN/CL-20}

In Figure 7, except for the D1 sample which had two partially overlapping exothermic peak, the DSC curves of D2-D4 samples displayed one exothermic peak, which was attributed to the decomposition of DFTNAN. The peak temperatures of these samples were noted to be lower than A1. The $\Delta T_{\mathrm{p}}$ values for the D1-D4 samples were more than $20^{\circ} \mathrm{C}$, while the result indicated these compositions to be incompatible.

On increasing the CL-20 content, two exothermic peaks were observed in the DSC curves of D5 and D6 sample, which correspond to the decompositions of CL-20 and DFTNAN, respectively. The first peak became weaker, whereas the second peak became stronger on increasing the CL-20 content. It indicated that the DFTNAN/CL-20 mixture with the mass ratios of 50:50 and 40:60 were incompatible. 
For the DFTNAN/CL-20 mixture with mass ratio of 30:70, 20:80 and 10:90, only a single exothermic peak was noted, which corresponded to the decomposition of CL-20. The $\Delta T_{\mathrm{p}}$ values of the samples indicated that CL-20 was compatible with DFTNAN.

\subsubsection{DFTNAN/TKX-50}

In Figure 8, for the mass ratios of the high explosives in the DFTNAN/TKX-50 compositions less than $60 \%$, only a single exothermic peak was noted, which was ascribed to the decomposition of DFTNAN. The peak temperatures of these samples were noted to be lower than $\mathrm{A} 1$. The $\Delta T_{\mathrm{p}}$ values for the E1-E6 samples were more than $20^{\circ} \mathrm{C}$, while the result indicated these compositions to be incompatible.

On further increasing the TKX-50 content, three exothermic peaks were observed in the DSC curves of E7, E8 and E9. Among these, the first peak was attributed to DFTNAN, and the $\Delta T_{\mathrm{p}}$ values were noted to be 113,118 and $119^{\circ} \mathrm{C}$, respectively. The second and third peaks were attributed to TKX-50 and were lower than the peak temperature of A5 $(26,19$, $15^{\circ} \mathrm{C}$ and $5,5,12^{\circ} \mathrm{C}$, respectively). This indicated that TKX-50 was incompatible with DFTNAN, and the thermal stability of pure explosive was reduced by mixing DFTNAN with TKX-50. It should be noted that the peak temperature of the third exothermic peak of E8 was higher than that of the second decomposition peak of TKX-50. Thus, it could be suggested that the addition of DFTNAN affected the thermal decomposition characteristics of TKX-50.

\section{Conclusions}

The thermal decomposition behavior of DFTNAN was investigated by DSC and TG using different heating rates $\left(2,5,10\right.$ and $\left.15^{\circ} \mathrm{C} \cdot \mathrm{min}^{-1}\right)$. The peak decomposition temperature $\left(T_{\mathrm{p}}\right)$ was observed in the range $252-298^{\circ} \mathrm{C}$, whereas the melting temperature was about $82{ }^{\circ} \mathrm{C}$. The TG curves exhibited a single step decomposition for different heating rates, and the mass loss rate was close to $100 \%$.

By applying the DSC data, the kinetic and thermodynamic thermal decomposition parameters, as well as the thermal safety parameters of DFTNAN, were calculated. The apparent activation energy $\left(E_{k, 0}\right)$ and pre-exponential factor $\left(A_{\mathrm{k}}\right)$ for the thermal decomposition of DFTNAN were estimated by the Ozawa and Kissinger methods. The values of $E_{\mathrm{k}}, A_{\mathrm{k}}$ and $E_{0}$ were determined to be $97.93 \mathrm{~kJ} \cdot \mathrm{mol}^{-1}, 4.73 \times 10^{8} \mathrm{~min}^{-1}$ and $101.78 \mathrm{~kJ} \cdot \mathrm{mol}^{-1}$, respectively.

The entropy $\left(\Delta S^{\neq}\right)$, enthalpy $\left(\Delta H^{\neq}\right)$and Gibbs free energy $\left(\Delta G^{\neq}\right)$of activation at $T_{\mathrm{p}}$ as well as the critical temperature of thermal explosion $\left(T_{\mathrm{b}}\right)$ and self-accelerating decomposition temperature $\left(\mathrm{T}_{A S D T}\right)$ were calculated as follows: $\Delta S^{\neq}=-92.10 \mathrm{~kJ} \cdot \mathrm{mol}^{-1} \cdot \mathrm{K}^{-1}$, $\Delta H^{\neq}=95.28 \mathrm{~kJ} \cdot \mathrm{mol}^{-1}, \Delta G^{\neq}=146.04 \mathrm{~kJ} \cdot \mathrm{mol}^{-1}, T_{\mathrm{ASDT}}=226.33^{\circ} \mathrm{C}$ and $T_{b}=249.03^{\circ} \mathrm{C}$. The observed thermal parameters confirmed that DFTNAN possessed superior thermal safety and stability. The research results further confirm the potential of DFTNAN as a substitute for melt-casting carrier, and provide a basis for the development, production and storage of explosives.

For the mass ratios of the high explosives in the DFTNAN/RDX mixture no less than $40 \%$, the DFTNAN and RDX have good compatibility. The DFTNAN/HMX mixture with the mass ratios of 40:60, 30:70, 20:80 and 10:90 revealed optimal compatibility. The DFTNAN/CL-20 mixture with the mass ratios of 30:70, 20:80 and 10:90 have good compatibility. On the other hand, DFTNAN was noted to be incompatible with TKX-50. As some basic data, further research on the formula design and cocrystal explosive of DFTNAN/HMX, DFTNAN/RDX and DFTNAN/CL-20 will be carried out, focusing on the study of DFTNAN/CL-20 based casting formula.

Author Contributions: Conceptualization, Y.-C.L. and S.-M.J.; investigations, F.H., L.-J.W., P.L. and W.Z.; data curation P.L., L.-J.W. and F.H.; Formal analysis, F.H., L.-J.W., W.Z. and J.-X.H.; writingoriginal draft preparation, F.H., L.-J.W., W.Z., P.L. and J.-X.H.; writing-review and editing, F.H., Y.-C.L., S.-M.J., L.-J.W. and J.-X.H. All authors have read and agreed to the published version of the manuscript. 
Funding: We acknowledge the financial support from the 17th postgraduate science and technology project of North University of China [No. 20201764], and the National Natural Science Foundation of China [No. 21875061, No. 21975066].

Institutional Review Board Statement: Not applicable.

Informed Consent Statement: Not applicable.

Data Availability Statement: Data sharing is not applicable to this article.

Acknowledgments: Sincere thanks to all the authors for their hard work on this article.

Conflicts of Interest: The authors declare no conflict of interest.

\section{References}

1. Li, Y.; Yuan, J.M.; Zhao, W.; Qu, Y.; Xing, X.W.; Meng, J.W.; Liu, Y.C. Application and Development of 3,4-Bis(3-nitrofurazan-4yl)furoxan (DNTF). Russ. J. Gen. Chem. 2021, 91, 445-455. [CrossRef]

2. Ou, Y.X. Explosives; Beijing Institute of Technology Press: Beijing, China, 2014; pp. 387-388. ISBN 978-7-5640-8621-3.

3. Agrawal, J.P.; Hodgson, R.D. Organic Chemistry of Explosives; John Wiley \& Sons: Chichester, UK, 2006.

4. Anniyappan, M.; Talawar, M.B.; Sinha, R.K.; Murthy, K.P.S. Review on Advanced Energetic Materials for Insensitive Munition Formulations. Combust. Explos. Shock. Waves 2020, 56, 495-519. [CrossRef]

5. Vijayalakshmi, R.; Radhakrishnan, S.; Shitole, P.; Pawar, S.J.; Mishra, V.S.; Garg, R.K.; Talawar, M.B.; Sikder, A.K. Spherical 3-nitro-1,2,4-triazol-5-one (NTO) based melt-cast compositions: Heralding a new era of shock insensitive energetic materials. RSC Adv. 2015, 5, 101647-101655. [CrossRef]

6. Smith, M.W.; Lu, J.P. Aging of the Insensitive Explosive, ARX-4024; DSTO Systems Sciences Laboratory: Edinburgh, UK, 2004.

7. Hang, G.-Y.; Yu, W.-L.; Wang, T.; Wang, J.-T.; Li, Z. Comparative studies on structures, mechanical properties, sensitivity, stabilities and detonation performance of CL-20/TNT cocrystal and composite explosives by molecular dynamics simulation. J. Mol. Model. 2017, 23, 281. [CrossRef]

8. Meng, J.-J.; Luo, Y.-M.; Niu, G.-T.; Wang, H.-X.; Yang, F. Effect of additives on the interface binding strength of DNAN/HMX melt-cast explosives. J. Energ. Mater. 2020, 38, 467-482. [CrossRef]

9. Mishra, V.; Vadali, S.; Bhagat, A.; Garg, R.; Kugaonkar, V.; Subramanian, R.; Sinha, R.; Asthana, S. Studies on NTO-, FOX-7- and DNAN-based Melt Cast Formulations. Central Eur. J. Energ. Mater. 2017, 14, 403-417. [CrossRef]

10. Ou, Y.X.; Han, T.J.; Rui, J.H.; Zhao, Y. High Energy Materials; National Defense Industry of Press: Beijing, China, 2013; pp. 85, 86, 140, ISBN 978-7-118-08692-8.

11. Yang, R.; Dong, Z.; Ye, Z. Tetrazolium Nitrate Anion Based Salts as Potential Melt-Castable Explosives. ChemistrySelect 2019, 4, 14208-14213. [CrossRef]

12. Wang, H.X.; Wang, X.F.; Luo, Y.M. Research Status and Development Trend of Insensitive Melt-Cast Explosive. Explos. Mater. 2021, 50, 4-12. [CrossRef]

13. Tang, W.Q.; Ren, H.; Jiao, Q.J.; Zheng, W. Property Characterization of 3,4-Dinitropyrazole and its Application. Chin. J. Energ. Mater. 2017, 25, 44-48. [CrossRef]

14. Hervé, G.; Roussel, C.; Graindorge, H. Selective Preparation of 3,4,5-Trinitro-1H-Pyrazole: A Stable All-Carbon-Nitrated Arene. Angew. Chem. 2010, 122, 3245-3249. [CrossRef]

15. Anniyappan, M.; Varma, K.V.; Amit, R.; Nair, J. 1-methyl-2,4,5-trinitroimidazole (MTNI), a melt-cast explosive: Synthesis and studies on thermal behavior in presence of explosive ingredients. J. Energetic Mater. 2019, 38, 111-125. [CrossRef]

16. Lian, P.-B.; Chen, J.; Chen, L.-Z.; Zhao, C.-Y.; Wang, J.-L.; Shen, F.-F. Preparation of 1-methyl-2,4,5-trinitroimidazole from derivatives of 1-methylimidazole and its oxidation under nitration conditions. Chem. Heterocycl. Compd. 2020, 56, 55-59. [CrossRef]

17. Li, X.; Wang, B.-L.; Lin, Q.-H.; Chen, L.-P. Compatibility Study of DNTF with Some Insensitive Energetic Materials and Inert Materials. J. Energetic Mater. 2016, 34, 409-415. [CrossRef]

18. Price, D.; Morris, J. Synthesis of DNMT: A New Energetic Melt-pour Ingredient. In Proceedings of the Insensitive Munitions and Energetic Materials Technology Symposium, Munich, Germany, 11-13 October 2010.

19. Altenburg, T.; Klapötke, T.M.; Penger, A. Primary nitramines related to nitroglycerine: 1-nitramino-2,3-dinitroxypropane and 1,2,3-trinitraminopropane. Cent. Euro. J. Energ. Mater. 2009, 6, 255-275.

20. Jing, S.; Jiang, Z.; Jiao, Q.; Li, Z.; Liu, Y.; Yang, L. 3,5-difluoro-2,4,6-trinitroanisole: Promising melt-cast insensitive explosives instead of TNT. J. Energ. Mater. 2021, 1-12. [CrossRef]

21. Hu, Y.F.; Gu, W.B.; Liu, J.Q.; Wang, H.X.; Huang, H.; Xu, J.L. Numerical study on Propagation of Stress Wave in Aluminum Foam Sandwiched Plates. Explo. Mater. 2014, 43, 21-25. [CrossRef]

22. Kissinger, H.E. Reaction Kinetics in Differential Thermal Analysis. Anal. Chem. 1957, 29, 1702-1706. [CrossRef]

23. Ozawa, T. A New Method of Analyzing Thermogravimetric Data. Bull. Chem. Soc. Jpn. 1965, 38, 1881-1886. [CrossRef]

24. Xiao, L.-B.; Zhao, F.-Q.; Luo, Y.; Li, N.; Gao, H.-X.; Xue, Y.-Q.; Cui, Z.-X.; Hu, R.-Z. Thermal behavior and safety of dihydroxylammonium 5,5'-bistetrazole-1,1'-diolate. J. Therm. Anal. Calorim. 2015, 123, 653-657. [CrossRef] 
25. Zhang, S.; Zhang, J.; Kou, K.; Jia, Q.; Xu, Y.; Liu, N.; Hu, R. Standard Enthalpy of Formation, Thermal Behavior, and Specific Heat Capacity of 2HNIW.HMX Co-crystals. J. Chem. Eng. Data 2018, 64, 42-50. [CrossRef]

26. Liu, Y.; Jiang, Y.-T.; Zhang, T.-L.; Feng, C.-G.; Yang, L. Thermal kinetic performance and storage life analysis of a series of high-energy and green energetic materials. J. Therm. Anal. Calorim. 2014, 119, 659-670. [CrossRef]

27. Yi, J.-H.; Zhao, F.-Q.; Wang, B.-Z.; An, T.; Wang, Y.; Gao, H.-X. BTATz-HNIW-CMDB propellants. J. Therm. Anal. Calorim. 2013, 115, 1227-1234. [CrossRef]

28. Yan, Q.-L.; Xiao-Jiang, L.; La-Ying, Z.; Ji-Zhen, L.; Hong-Li, L.; Zi-Ru, L. Compatibility study of trans-1,4,5,8-tetranitro-1,4,5,8tetraazadecalin (TNAD) with some energetic components and inert materials. J. Hazard. Mater. 2008, 160, 529-534. [CrossRef] [PubMed]

29. De Klerk, W.P.C.; Schrader, M.A.; Van Der Steen, A.C. Compatibility Testing of Energetic Materials, Which Technique? J. Therm. Anal. Calorim. 1999, 56, 1123-1131. [CrossRef]

30. Muravyev, N.V.; Monogarov, K.; Asachenko, A.F.; Nechaev, M.S.; Ananyev, I.V.; Fomenkov, I.V.; Kiselev, V.; Pivkina, A. Pursuing reliable thermal analysis techniques for energetic materials: Decomposition kinetics and thermal stability of dihydroxylammonium 5,5'-bistetrazole-1,1'-diolate (TKX-50). Phys. Chem. Chem. Phys. 2016, 19, 436-449. [CrossRef]

31. Lee, J.-S.; Hsu, C.-K.; Chang, C.-L. A study on the thermal decomposition behaviors of PETN, RDX, HNS and HMX. Thermochim. Acta 2002, 392-393, 173-176. [CrossRef]

32. Kimura, J.; Kubota, N. Thermal Decomposition Process of HMX. Propellants Explos. Pyrotech. 1980, 5, 1-8. [CrossRef] 